\title{
The existence of policies, practices and perceptions regarding children as visitors to public hospitals in uMgungundlovu, KwaZulu-Natal Province
}

\author{
P Appalsamy, ${ }^{1} \mathrm{MB} \mathrm{ChB}, \mathrm{DCH}(\mathrm{SA}), \mathrm{HIV}$ Dip Man (SA), FC Paed (SA); \\ N H McKerrow, ${ }^{1,2}$ MB ChB, BA, DCH (SA), FC Paed (SA), MMed (Paeds), PG Dip Int Res Ethics \\ ${ }^{1}$ Department of Paediatrics and Child Health, Nelson R Mandela School of Medicine, Faculty of Health Sciences, University of \\ KwaZulu-Natal, Durban, South Africa \\ ${ }^{2}$ Department of Health KwaZulu-Natal, Durban, South Africa
}

Corresponding author: P Appalsamy (pranesha_appalsamy@yahoo.com)

\begin{abstract}
Background. Current policies and practices regarding child visitors in hospitals in uMgungundlovu, KwaZulu-Natal Province, South Africa, are unknown. Existing literature focuses on provision for child visitors in specialised units in well-resourced countries. Objective. To identify policies, describe current practices and determine the perceptions of healthcare workers to child visitors. Methods. Interviews were conducted with 7 nursing managers regarding the existence and content of a hospital visitors' policy, 12 operational managers (OMs) to describe ward practices regarding child visitors, and 12 professional nurses and 11 doctors to determine their attitudes towards children as visitors in all four general state hospitals in uMgungundlovu between October 2013 and July 2015.

Results. Five out of seven nursing managers were aware of a visitors' policy in their hospital. These policies allowed children to visit family or parents in adult wards, but only 2 would allow children to visit a family member and only 1 would allow visits to a friend in the children's wards. According to the nursing managers, policy was that the visitor must be over 5 years of age to visit in an adult ward while 2 out of 3 nursing managers allowed only children over 12 years of age to visit in children's wards. Visits must occur during prescribed visiting times and the visitor must be accompanied by an adult. In practice, 7 out of 12 OMs allow child visitors in their wards. Only 2 out of 7 OMs allow unrestricted visitation by children and only to non-infectious patients in children's wards - this is subject to variable age restrictions in adult wards and an age limit of 12 years in children's wards. In all wards, visits by children are restricted to prescribed visiting times and conditional on an adult escort. Three out of seven OMs allow 2 visitors only, although most (5 out of 7) allow visits of unlimited duration. Staff who favoured child visitors were more likely to be younger, male and employed as health professionals for $<5$ years. More doctors than nurses believed that children should be allowed to visit family and/or friends in hospital. Justifications for not allowing children to visit centred on infection risks and the emotional trauma of visiting a sick loved one. The child, patient and health professional were seen to benefit socially from child visitors, although there are positive and negative emotional consequences for the patient and the child.

Conclusion. Hospitals do make provisions for visitors, but most exclude young children, particularly those who are most vulnerable to the negative consequences of separation from a parent or family member. While policies do exist to guide child visitation in uMgungundlovu, such policies are restrictive, inconsistent and do not necessarily reflect day-to-day practices.
\end{abstract}

S Afr J Child Health 2016;10(3):171-175. DOI:10.7196/SAJCH.2016v10i3.1098

Disruption of the family unit by hospitalisation can cause major physical and psychological stress for patients and their families, particularly children. Flexible visiting policies are advocated as a positive intervention to help families cope with the stress of illness. Current surveys, conducted in the adult critical care setting in wellresourced countries, have shown that children are still restricted from visiting. ${ }^{[1]}$ Reasons for such restrictions stem from children disrupting the running of the unit, nurses being unable to cope with their queries and emotions, physicians disapproving of visits and the risk of infection. However, no evidence has been found that visiting children are more prone to infection. ${ }^{[2]}$

Knutssen et al. ${ }^{[3]}$ showed that children actually benefit from visits through increased understanding and involvement in the wellbeing of their family as well as reduced feelings of separation, guilt, fear, helplessness and abandonment.

In South Africa (SA), hospital visiting policies are available to the public online. In Groote Schuur Hospital, ${ }^{[4]}$ a maximum of three visitors are allowed per patient in the general ward and two in the maternity wards and intensive care unit (ICU). Children $<12$ years old are not permitted to visit unless the patient is the parent or sibling and only if supervised by an accompanying adult. If a patient's condition deteriorates, visiting is at the discretion of the sister in charge and the duration of the visit restricted if it is considered to be detrimental to the patient's wellbeing. Steve Biko Academic Hospital ${ }^{[5]}$ does not allow children to visit paediatric wards for infection control purposes. Similarly, Inkosi Albert Luthuli Central Hospital ${ }^{[6]}$ does not allow children $<12$ years in the hospital. While hospitals allow both adult and paediatric patients to be visited by family and friends, most exclude children as visitors. Existing literature $e^{[1-3,7-9]}$ regarding children as visitors to hospitals is limited to ICUs in well-resourced countries. No studies are available on current policies or practices regarding child visitors locally, in SA, or in other resource-limited, non-critical-care settings. This study was undertaken to describe current policies, practices and perceptions of healthcare workers (HCWs) to child visitors in public sector hospitals in the uMgungundlovu district of KwaZulu-Natal (KZN) Province, SA.

\section{Methods}

uMgungundlovu comprises 7 municipalities, within which there are 9 state hospitals -4 are general hospitals, 2 are for TB and 3 are psychiatric hospitals. All four general state hospitals agreed to participate in the study but two private hospitals that were invited to participate declined the invitation. This descriptive study was 
undertaken in the four general state hospitals in uMgungundlovu, including district, regional and tertiary hospitals in urban, periurban and rural settings. In each hospital, staff who had worked in the relevant ward for at least 3 months were recruited from an adult female, an adult male and a children's ward. Specialised hospitals and temporary or newly appointed staff in general hospitals were excluded. Three groups of health professionals were interviewed using questionnaires aimed at determining the following information: (i) nursing managers: regarding the existence and content of a hospital visitor's policy; (ii) ward operational managers (OMs): to describe practices and the rationale regarding child visitors; and (iii) professional nurses (PNs) and doctors: to determine their attitudes towards children as visitors in their wards. Questionnaires were not piloted prior to administration and hospital visitor policies were not collected to validate the findings. Ethical approval was obtained from the Biomedical Research Ethics Committee of the University of KZN.

\section{Results}

A total of 42 participants were interviewed, 39 personally and 3 telephonically, including 7 nurse managers, 12 OMs, 12 PNs and 11 doctors, representing adults' and children's wards. Table 1 depicts the responses of nursing managers regarding the existence of a hospital visitors' policy and details of how long it has existed, how often it is reviewed and the various stipulations pertaining to the patient and visits from children.

Five out of seven nursing managers were aware of a visitors' policy in their hospital, and the remaining two reported using the infection prevention and control policy instead. When present, most of the visitors' policies had existed for more than 10 years, were developed within the hospital and were reviewed annually. The policies made provision for visits:

- to all patients in adult wards, but 2 out of 3 restricted visits to non-infectious cases in children's wards

- by anyone $>5$ years of age in adult wards, but only by people $>12$ years of age in children's wards

- during prescribed visiting times in adult wards, while 1 out of 3 allowed visitors at any time in children's wards

- restricted to 2 visitors at a time in 3 of the 5 policies according to the nursing managers.

The policies allowed child visitors:

- to family or parents in an adult ward, but only 2 out of 3 allowed children to visit family members and only 1 out of 3 allowed children who are friends to visit a patient in a children's ward

Table 1. Visitor policy according to nurse managers

\begin{tabular}{llll}
\hline & $\begin{array}{l}\text { Adult nurse manager } \\
(n=3)\end{array}$ & $\begin{array}{l}\text { Paediatric nurse } \\
\text { manager }(n=4)\end{array}$ & $\begin{array}{l}\text { Total } \\
(N=7)\end{array}$ \\
\hline $\begin{array}{l}\text { Policy } \\
\text { Policy available }\end{array}$ & 2 & 3 & 5 \\
$\quad \begin{array}{l}\text { Duration of policy }>10 \text { years } \\
\text { Frequency of review }\end{array}$ & 1 & 3 & 4 \\
$\quad \begin{array}{l}\text { Annual } \\
5 \text { years }\end{array}$ & 2 & 2 & 4 \\
Patient & - & 1 & 1
\end{tabular}

Patient

Who may be visited

All patients

Non-infectious

Who is allowed to visit

Unrestricted

Restricted

Visiting times

Unrestricted

Restricted

Number of visitors allowed

Unlimited

Two only

Child visitors

Who may they visit

Parents

Family

Anyone

Who may visit

Any age

$>5$ years

$>12$ years

Prescribed visiting times

Children must be accompanied by an adult

Reasons for not allowing visits

Infection control

Emotional trauma

Separation anxiety

- to adult wards if they are $>5$ years of age, and 2 out of 3 only allowed children $>12$ years of age to visit in children's wards - during prescribed visiting times in both wards if accompanied.

Justifications for these restrictions are to: protect children from infection; spare them from emotional trauma; and avoid separation anxiety. Table 2 reflects the responses of the OMs in the wards regarding the existence of a hospital visitors' policy and their day-to-day practice in terms of the stipulations of the policies pertaining to both the patient and child visitor.

Of the 12 OMs, 7 allowed child visitors in their wards. The remainder excluded children to limit their exposure to infections, and in one adult ward out of concern that psychiatric/mentally unstable patients could pose a threat to the children. Only two OMs in adult wards allowed children to visit any category of patient, but the remaining two and all OMs in children's wards would only allow children to visit non-infectious patients. 
Table 2. Visitor practices according to ward OM

\begin{tabular}{|c|c|c|c|}
\hline & $\begin{array}{l}\text { Adult ward } \\
\text { OM }(n=8)\end{array}$ & $\begin{array}{l}\text { Paediatric ward } \\
\text { OM }(n=4)\end{array}$ & $\begin{array}{l}\text { Total } \\
(N=12)\end{array}$ \\
\hline \multicolumn{4}{|l|}{ Policy } \\
\hline Availability of policy & 7 & 3 & 10 \\
\hline \multicolumn{4}{|l|}{ Practice } \\
\hline Allow children to visit & 4 & 3 & 7 \\
\hline \multicolumn{4}{|l|}{ Reasons if not allowed } \\
\hline Infection control & 4 & 3 & 7 \\
\hline Hazardous & 1 & 3 & 1 \\
\hline \multicolumn{4}{|c|}{ Patient - who may be visited } \\
\hline All patients & 2 & - & 2 \\
\hline Non-infectious & 2 & 3 & 5 \\
\hline \multicolumn{4}{|c|}{ Child visitors - who may be visited } \\
\hline Parents & - & - & - \\
\hline Family & 4 & 2 & 6 \\
\hline Anyone & - & 1 & 1 \\
\hline \multicolumn{4}{|l|}{ Who may visit } \\
\hline Any age & 1 & - & 1 \\
\hline$>5$ years & 1 & - & 1 \\
\hline$>12$ years & 2 & 3 & 5 \\
\hline $\begin{array}{l}\text { Visiting times - } \\
\text { prescribed }\end{array}$ & 4 & 3 & 7 \\
\hline $\begin{array}{l}\text { Children must be } \\
\text { accompanied }\end{array}$ & 4 & 3 & 7 \\
\hline \multicolumn{4}{|l|}{ Number of child visitors } \\
\hline Unlimited & 2 & 1 & 3 \\
\hline Two only & 1 & 2 & 3 \\
\hline Other & 1 & - & 1 \\
\hline \multicolumn{4}{|l|}{ Length of time allowed } \\
\hline Limited & 1 & 1 & 2 \\
\hline Unlimited & 3 & 2 & 5 \\
\hline
\end{tabular}

Children may visit only family in adult wards but anyone in children's wards - subject to variable age restrictions in adult wards and an age limit of 12 years in children's wards. In all wards, visits by children were restricted to prescribed visiting times and under adult supervision. Three out of 7 OMs allowed two visitors at a time and most (5 out of 7) allowed visits of unlimited duration. More doctors than nurses believed that children should be allowed to visit family and/or friends in hospital (Table 3). More doctors (8 out of 11) would allow children to visit family and/or friends than nurses (5 out of 12). All 4 doctors but only 2 out of 4 PNs in children's wards would allow child visitors. A similar pattern was found among staff in the adult ward, although three-quarters of PNs in female wards but none in male wards would allow child visitors. Staff who would allow child visitors tended to be: - younger: 6 out of 8 among 20 - 29-year-olds would allow child visitors, reducing to 2 out of 5 at 40 - 49 years

- male: 4 out of 5 would allow child visitors compared with 9 out of 18 of female staff

- employed as health professionals for $<5$ years: 5 out of $6 \mathrm{v}$. 3 out of 8 of staff employed for 5 - 10 years and 5 out of 9 of those employed for $>10$ years.
Table 3 describes the perceptions of PNs and doctors towards the patient being visited by children and explores the reasons for various decisions. More doctors than nurses believed children should be allowed to visit sick family and/or friends. For both cadres this was true for a greater proportion of staff in paediatric than adult wards. Reasons for restricting children centred on infection risks and the emotional trauma of visiting a sick loved one. Contrary to this, one doctor felt children should only be allowed to visit the terminally ill. Most staff believed that only select patients should be visited, with both nurses and doctors relating this restriction to infection risks and emotional trauma of visiting a sick loved one. Doctors felt that the hospital environment can be hazardous for children and that only terminally ill patients should get preference with regard to child visitors. Staff who would allow all patients to be visited would do so to strengthen family ties (all doctors held this belief) and respect patient's rights. Nurses felt that the patient should be stable and provisions could be made to facilitate visits to infectious patients. Staff also believed in restricting whom children can visit. Doctors confined visits to family members, while 2 out of 5 nurses supported visits to friends too. Half of doctors, but only 1 out of 5 nurses, believed children of any age should be allowed to visit. Most nurses would restrict child visitors to those $>12$ years, while 2 out of 8 doctors suggested maturity rather than age should determine which children can visit. All staff believed child visitors should be restricted to prescribed visiting times and accompanied during visitation. Most staff, especially nurses and those in adult wards, would limit the number of visitors but not the duration of the visit. With regard to consequences of child visitors, HCWs felt that all three cadres, the child, the patient and the health professional, benefitted socially, while there are positive and negative emotional consequences for the patient and child. Reported benefits for the child included the joy of seeing his/her parent/family and reassurance regarding their presence/existence and wellbeing. Benefits for the patient included happiness at seeing their child, strengthening family bonds and speedier recovery. Deleterious consequences for the child centered on infection risks and the emotional trauma of seeing terminally ill patients. Negative effects on the patient focused on emotional upset and possible depression after the child leaves. Furthermore, the parent/caregiver may not want to be seen as physically unfit to the child. Benefits to the HCW focused on improvement of in-patient care, clinical outcomes and recovery time, thereby decreasing their burden of work. The main emotional advantage included having to deal with a patient who does not have anxiety and stress caused by thinking of his/her children at home. Key disadvantages were the disruption child visitors can cause to the ward routine and need for the supervision and control of unruly children. Moreover, HCWs were concerned about the child's health and safety, and having to deal with a child who reacts negatively to an ill patient.

\section{Discussion}

Not all nursing managers in hospitals in uMgungundlovu reported the existence of a hospital visitors' policy. Available policies defined the category of the patient to be visited, his/her relationship to the visitor, the number and age of child visitors allowed, as well as the times and duration of visits. With regard to child visitor practices, differences were noted among the three cadres of staff, with 7 out of 12 OMs, 5 out of 12 PNs and 8 out of 11 doctors supporting child visitors. This differs from international experience of ICU visiting policies that, despite being specialised units, are less restrictive on child visitors. Quinio et al. ${ }^{[7]}$ found that only $11 \%$ of 200 ICUs in France excluded children as visitors, while only $3.9 \%$ of ICUs in a UK survey ${ }^{[8]}$ did not permit children. Similarly, in 69 US hospitalbased maternity units, only $5.8 \%$ did not allow any children to visit. ${ }^{[9]}$ While only 1 out of the 5 nursing managers (who were aware of a visitor's policy) indicated that their policy allowed children to visit 
Table 3. Perceptions of PN and doctors regarding child visitors

\begin{tabular}{|c|c|c|c|c|c|c|}
\hline & \multicolumn{2}{|c|}{ Adult ward } & \multicolumn{2}{|c|}{ Paediatric ward } & \multicolumn{2}{|c|}{ Total } \\
\hline & $\begin{array}{l}\mathrm{PN} \\
(n=8)\end{array}$ & $\begin{array}{l}\text { Doctor } \\
(n=7)\end{array}$ & $\begin{array}{l}\mathrm{PN} \\
(n=4)\end{array}$ & $\begin{array}{l}\text { Doctor } \\
(n=4)\end{array}$ & $\begin{array}{l}\mathrm{PN} \\
(N=12)\end{array}$ & $\begin{array}{l}\text { Doctor } \\
(N=11)\end{array}$ \\
\hline \multicolumn{7}{|l|}{ Perception } \\
\hline Children should be allowed to visit & 3 & 4 & 2 & 4 & 5 & 8 \\
\hline \multicolumn{7}{|l|}{ Reasons if not allowed } \\
\hline Infection control & 4 & 1 & 2 & - & 6 & 1 \\
\hline Emotional trauma & - & 1 & 1 & - & 1 & 1 \\
\hline No reason given & 1 & - & - & - & 1 & - \\
\hline Preference to terminally ill only & - & 1 & - & - & 1 & - \\
\hline \multicolumn{7}{|l|}{ Patient } \\
\hline Who may be visited - all patients & 2 & 1 & 1 & 1 & 3 & 2 \\
\hline \multicolumn{7}{|l|}{ Reasons for restrictions } \\
\hline Infection control & 5 & 4 & 2 & 2 & 7 & 6 \\
\hline Emotional trauma & 1 & 3 & 1 & - & 2 & 3 \\
\hline Patient dependent & - & 1 & - & 1 & - & 2 \\
\hline Hazardous environment & - & - & - & 1 & - & 1 \\
\hline \multicolumn{7}{|l|}{ Reasons for allowing visit } \\
\hline Family bonding & 1 & - & - & - & 1 & \\
\hline Patient's right & 1 & 1 & - & - & 1 & 1 \\
\hline Special provisions & 1 & - & - & - & 1 & \\
\hline Patient dependent & - & - & 1 & 1 & 1 & 1 \\
\hline \multicolumn{7}{|l|}{ Child visitors - who may be visited } \\
\hline Parents & 1 & 1 & - & - & 1 & 1 \\
\hline Family & 1 & 3 & 1 & 4 & 2 & 7 \\
\hline Anyone & 1 & - & 1 & - & 2 & \\
\hline \multicolumn{7}{|l|}{ Who may visit } \\
\hline Any age & - & 2 & 1 & 2 & 1 & 4 \\
\hline$>5$ years & 1 & 1 & - & 1 & 1 & 2 \\
\hline$>12$ years & 2 & - & - & - & 3 & - \\
\hline Other & - & 1 & 1 & 1 & - & 2 \\
\hline Visiting times - prescribed & 3 & 4 & 2 & 4 & 5 & 8 \\
\hline Must children be accompanied & 3 & 4 & 2 & 4 & 5 & 8 \\
\hline \multicolumn{7}{|l|}{ Number of child visitors } \\
\hline Unlimited & - & 2 & 1 & 1 & 1 & 3 \\
\hline 2 only & 2 & 1 & 1 & 1 & 3 & 2 \\
\hline 1 only & 1 & 1 & - & 1 & 1 & 2 \\
\hline Other & - & - & - & 1 & & 1 \\
\hline \multicolumn{7}{|l|}{ Length of time allowed } \\
\hline Limited & 1 & 1 & 1 & 2 & 2 & 3 \\
\hline Unlimited & 2 & 3 & 1 & 2 & 3 & 5 \\
\hline
\end{tabular}

without any age limit, this is not common practice. Only 1 out of 7 allowed child visitors of any age, and 5 OMs limited visits to children $>12$ years. Age restrictions are common, and 12 years is the most common threshold for child visitors. This threshold is applicable in $76.9 \%$ of ICUs in Brazil ${ }^{[10]}$ and in $44 \%$ of French units that fixed a minimum age limit for visits; the mean age limit was also 12 years. $^{[7]}$ Similarly, some children's hospitals in the USA only allow child visitors above 12 years old, while others screen for illness before allowing visitation. ${ }^{[11-13]}$ Local restrictions are more severe than those in published reports: $46 \%$ of child visitors in French ICUs ${ }^{[7]}$ are allowed to visit without age limits, while $28.9 \%$ of US maternity wards ${ }^{[9]}$ allowed open visitation for children during the intrapartum period, rising to $82.6 \%$ during the postpartum period. Open visitation was defined as no restrictions based on the child's age, relationship to the mother or specific visiting hours, and only $5.8 \%$ of units physically assessed or observed children for signs of illness prior to visiting. PNs in our study were more supportive of child visitation in the female than the male wards, possibly indicating preference given to maternal rather than paternal caregivers. According to the visitors' policy in our hospitals, 3 out of 5 nursing managers would allow all patients to be visited irrespective of their disease profile. However, only 1 would allow the patient to be visited by anyone - inclusive of both family and friends. In practice, this is reduced to only 2 out of 7 OMs allowing all patients to be visited and 1 out of 7 OMs allowing the patient to be visited by anyone, which demonstrates incongruences between policy and practice. However, nurses were more likely to allow unrestricted visitation to patients, and 2 out of 5 would allow visits to/both family and friends. This incongruency has been noted elsewhere where restrictive policies exist, but are not always enforced by nursing staff..$^{[9,14]}$ While only one of the staff felt that critically ill patients should get preference for visits by children, this perception is also evident in certain ICUs in the UK where visitation increased in the case of a dying patient. ${ }^{[8]}$ Two out of five nursing managers indicated that their visitors' policies allowed an unlimited number of visitors. This is endorsed by OMs, although nurses and doctors were more restrictive, with 1 out of 5 nurses and 3 out of 8 doctors allowing an unlimited number of visitors. This differs from many ICU visiting polices that allow just two visitors at a time. ${ }^{[7,8]}$

The literature describes three visiting policies pertaining to time limits. Open visitation allows families to visit at any time in a 24-hour period. Liberalised visiting allows visitors access at a time determined by the staff. Restrictive policies allow a fixed number of visitors at the same time for everyone. ${ }^{[7]}$ In this study, the visitors' policies prescribed restrictive visiting times that were enforced in adult wards but not in children's wards, a third of which practise open visitation. The policy is in accordance with ICUs in Europe and the UK that adopt restricted visiting hour policies. ${ }^{[7,8]}$

Many members of staff supported visits of unlimited duration; however, they did specify that children should be accompanied. Similarly, Ottawa General Hospital ${ }^{[15]}$ in 
Canada allows children under the age of 12 only if accompanied by an adult. In SA, current child visitor policies vary. Groote Schuur Hospital ${ }^{[4]}$ allows children under the age of 12 years to visit only if the patient is a parent or sibling of the child and provided that the child is under adult supervision. Steve Biko Academic Hospital ${ }^{[5]}$ does not allow children to visit in paediatric wards for infection control purposes. Inkosi Albert Luthuli Central Hospital ${ }^{[6]}$ does not allow children $<12$ years in the hospital.

The focus of available literature is on ICUs in well-resourced settings, which differ from the generalist hospitals included in our study. In exploring the perspectives of HCWs, child visitors were favoured more among the younger, less-experienced male staff. Years of training, past experience and specific experience within certain patient populations may contribute to the impression of perceived risk or benefit, leading to either restrictive or liberal practices. The most common reason cited for promoting restrictive policies was the protection of the child from infection and emotional distress. ${ }^{[7]}$

Child visitation has been shown to benefit both the child and the patient, particularly when this is a sibling, and children who are allowed to visit the neonatal ICU show less negative behaviour and more knowledge about their ill sibling. ${ }^{[16]}$ In this study, HCWs felt that the child and patient would benefit socially, while acknowledging the positive and negative emotional consequences. These concerns are in keeping with studies that have shown that one of the rationales for restrictive policies is to protect the patient from psychological stress that can be caused by the family. ${ }^{[7]}$

\section{Study limitations}

This was a small descriptive study in one health district in KZN; therefore, caution must be taken in interpreting and generalising the findings. Clearer definitions were required for the advantages and disadvantages of child visitors. Additionally, nursing managers' responses were not validated with the actual visitor policy for each hospital.

\section{Conclusion}

Available literature regarding child visitor policies and practices is based on developed countries, ICU settings and adult patient populations. This is in contrast to the generalist hospitals included in our study, reflecting both adult and children's wards. Hospitals do make provision for visitors, but most exclude young children who are most vulnerable to the negative consequences of separation from loved ones. Nevertheless, children need and have a right to visit parents and siblings admitted to hospital.
While policies do exist to guide child visitation in uMgungundlovu, they are restrictive, inconsistent and do not necessarily reflect day-today practices. Furthermore, the difference between practices and the views of different cadres of staff reflects the complexity of the subject. Attitudes to visiting children must therefore be discussed at all levels and a consensus based on the needs of the patient, child and HCW should be reached.

\section{Recommendation}

Liberalised hospital visitor policies that consider the rights of children should be available and implemented uniformly by all cadres of staff.

\section{References}

1. Clarke $\mathrm{C}$, Harrison D. The needs of children visiting our adult intensive care units: A review of the literature and recommendations for practice. J Adv Nurs 2001;34(1):61-68. DOI:10.1046/j.1365-2648.2001.3411733.x

2. Knutsson S, Bergbom I. Nurses' and physicians' viewpoints regarding children visiting/not visiting adult ICUs. Nurs Crit Care 2007;12(2):64-73. DOI:10.1111/ j.1478-5153.2007.00209.x

3. Knutsson S, Samuelsson IP, Hellström AL, Bergbom I. Children's experiences of visiting a seriously ill/injured relative on an adult intensive care unit. J Adv Nurs 2008;61(2):154-162. DOI:10.1111/j.1365-2648.2007.04472.x

4. Groote Schuur Hospital. Visiting hours. http://www.gsh.co.za (accessed 22 March 2016).

5. Steve Biko Academic Hospital. http://www.sbah.org.za/index.php/information/ important-information (accessed 22 March 2016).

6. Inkosi Albert Luthuli Central Hospital. Patients/Visitors. http://www.ialch. co.za (accessed 5 February 2016).

7. Quinio P, Savry C, Deghelt A, Guilloux M, Catineau J, de Tinténiac A. A multicenter survey of visiting policies in French intensive care units. Intensive Care Med 2002;28(10):1389-94. DOI:10.1007/s00134-002-1402-7

8. Hunter JD, Goddard C, Rothwell M, Ketharaju S, Cooper H. A survey of intensive care unit visiting policies in the United Kingdom. Anaesthesia 2010;65(11):1101-1105. DOI:10.1111/j.1365-2044.2010.06506

9. Spear HJ. Child visitation policy and practice for maternity units. MCN Am J Matern Child Nurs 2009;34(6):372-377. DOI:10.1097/01.NMC.000363686. 20315.d5

10. Fernando JSR, Renata RLF, Luciano CPA, Guilherme S. Intensive care unit visitation policies in Brazil: A multicenter survey. Rev Bras Ter Intensiva 2014;26(4):339-346. DOI:10.5935/0103-507X.20140052

11. Children's Hospital Colorado. Visitation policies at Children's Hospital Colorado. http://www.childrenscolorado.org (accessed 5 February 2016).

12. Boston Children's Hospital. For patients and families. http://www.childrenshospital.org (accessed 5 February 2016).

13. SickKids. Visiting SickKids. http://www.sickkids.on.ca (accessed 5 February 2016).

14. Simon SK, Phillips K, Badalamenti S, Ohlert J, Krumberger J. Current practices regarding visitation policies in critical care units. Am J Crit Care 1997;6(3):210 217. DOI:10.109700003246-199501001-00045

15. The Ottawa Hospital. Patients and visitors. http://www.ottawahospital.on.ca (accessed 5 February 2016).

16. Barkmann C, Romer G, Watson M, Schulte-Markwort M. Parental physical illness as a risk for psychosocial maladjustment in children and adolescents: Epidemiological findings from a national survey in Germany. Psychosomatics 2007;48(6):476-481. DOI:10.1179/appi.psy.48.6.476 